\title{
Influence of Surfactants and Fluoride against Enamel Erosion
}

\author{
Rayssa Ferreira Zanatta ${ }^{a}$ b Daniele Mara da Silva Ávila ${ }^{a}$ \\ Karen Mayumi Miyamoto ${ }^{a}$ Carlos Rocha Gomes Torres ${ }^{a}$ \\ Alessandra Bühler Borges ${ }^{a}$ \\ a Department of Restorative Dentistry, Institute of Science and Technology, São Paulo State University - UNESP, \\ São José dos Campos, Brazil; ${ }^{b}$ Department of Restorative Dentistry, Dental School, University of \\ Taubaté, Taubaté, Brazil
}

\section{Keywords}

Fluoride $\cdot \mathrm{pH}$ cycling $\cdot$ Profilometry $\cdot$ Salivary pellicle .

Surfactant

\section{Abstract}

This study investigated the effect of surfactants associated with sodium fluoride $(\mathrm{NaF})$ on enamel erosion prevention, using an erosion-remineralization in vitro model. Sodium lauryl sulfate (SLS), polysorbate 20 (P20), and cocoamidopropyl betaine (CAPB) were tested, at concentrations of 1.0 and $1.5 \%$, and associated or not with $\mathrm{NaF}(275 \mathrm{ppm})$. The control groups were distilled water and the $\mathrm{NaF}$ solution. Bovine enamel samples $(n=12)$ were prepared and submitted to a 5-day cycling model: acid challenge ( $0.3 \%$ citric acid, $\mathrm{pH}$ 2.6, $4 \times /$ day), human saliva ( $2 \mathrm{~h}, 4 \times /$ day), and the treatment solutions ( $2 \mathrm{~min}, 2 \times /$ day). The protective potential of the agents against initial erosion was assessed by microhardness and the surface loss by profilometry. Enamel surface wettability was determined by goniometry, protein adsorption was measured by spectroscopy (FTIR), and the $\mathrm{KOH}$-soluble fluoride was quantified. Goniometry showed that SLS and CAPB increased enamel wettability. No differences were found

\section{KARGER}

(๑) 2018 S. Karger AG, Basel

E-Mail karger@karger.com

www.karger.com/cre among the surfactants regarding protein adsorption. Microhardness showed that SLS reduced NaF protection. P20 (1 and $1.5 \%$ ) and CAPB $1.5 \%$ presented a protective effect, but lower than the $\mathrm{NaF}$ solution. Profilometry showed that $\mathrm{CAPB}$ protected enamel, but no agent associated with $\mathrm{NaF}$ promoted a higher protection than the $\mathrm{NaF}$ solution alone. $\mathrm{KOH}-$ soluble fluoride analysis showed that all surfactants reduced the fluoride adsorption on the enamel surface. Therefore, the surfactants tested (except for P20) changed the enamel surface energy. The SLS decreased the protective potential of $\mathrm{NaF}$ on initial erosion, but no tested agent interfered with the protective effect of $\mathrm{NaF}$ on enamel erosive wear.

(c) 2018 S. Karger AG, Basel

Dental erosion is a multifactorial process characterized by the chemical demineralization of tooth structures promoted by non-bacterial intrinsic or extrinsic acids and chelating agents [Lussi and Carvalho, 2014]. Before coming into contact with the enamel, the acid must diffuse through the acquired pellicle [Featherstone and Lussi, 2006]. The enamel acquired pellicle (EAP) is a film, free from bacteria, that covers dental tissues and is com- 
posed of several proteins, such as mucins, glycoproteins, and proline-rich proteins [Hannig et al., 2005; Buzalaf et al., 2012]. It acts as a diffusion barrier or semipermeable membrane that prevents the direct contact between the acids and the tooth surface [Lussi et al., 2011], thus protecting enamel against demineralization [Buzalaf et al., 2012; Vukosavljevic et al., 2014].

Oral hygiene products, such as dentifrices and mouthwashes, are commonly used to remove organic material from tooth surfaces and act over the biofilm control [Veeregowda et al., 2011]. Surfactants present in these products' composition can influence the adsorption of salivary proteins [van der Mei et al., 2002; Veeregowda et al., 2011], potentially affecting the EAP formation. Also, these oral hygiene products often contain fluorides, such as sodium fluoride, which presents a protective effect against dental erosion [Ganss et al., 2008; Jager et al., 2013]. This protective action is attributed to the interaction of fluoride with calcium [Magalhaes et al., 2009, 2011], decreasing the enamel dissolution rate. However, previous findings speculate that the presence of surfactants, such as sodium lauryl sulfate (SLS), can influence the fluoride ions' availability and their binding to tooth structures [Barkvoll et al., 1988b; Zero, 2006]. Additionally, detergents can interact with hydroxyapatite [Barkvoll et al., 1988a] and also modulate the abrasiveness of dentifrices [Moore and Addy, 2005].

Although SLS is the most common surfactant found in dentifrices, it is usually related to alterations in oral mucosa, affecting epithelial surfaces [Neppelberg et al., 2007]. Therefore, some products contain other surfactants, such as cocoamidopropyl betaine (CAPB) [Rantanen et al., 2002].

The influence of surfactants and their interaction with fluoride during erosive events have not been well established so far. Thus, the aim of this study was to evaluate the effect of surfactants in different concentrations over the enamel surface energy and their influence on the acquired pellicle formation and fluoride protection under erosive situations. The null hypotheses tested were that: (a) the surfactants do not change the enamel wettability and (b) do not interfere with fluoride protection during erosive challenges on enamel.

\section{Materials and Methods}

\section{Experimental Design}

The 3 experimental factors tested were: (1) the surfactant type: SLS, CAPB and polysorbate 20 (P20 - also known as Tween 20); (2) the surfactant concentration: 1.0 and $1.5 \% \mathrm{v} / \mathrm{v}$; (3) the presence of sodium fluoride (with or without $\mathrm{NaF}-275 \mathrm{ppm}$ ). The study variables were surface wettability characterized by contact angle, absorbance of proteins on enamel by Fourier transformed infrared (FTIR) spectroscopy, surface microhardness (SMH) for initial erosion analysis, surface loss $(\mu \mathrm{m})$ measured by contact profilometry for erosive wear assessment, and fluoride adsorption on enamel (KOH-soluble fluoride).

\section{Sample Preparation}

For the surface energy analysis, 35 crowns from freshly extracted bovine incisors were embedded in acrylic resin (Extec Fast Cure Acrylic, Extec Corp., Enfield, CT, USA) using a cylindrical silicone matrix. After curing, the specimens were flattened with $\mathrm{SiC}$ abrasive paper \#1,200 (FEPA P, Struers, Ballerup, Denmark) under irrigation at a polishing machine (DP-10, Panambra Industrial e Técnica SA, São Paulo, Brazil) until an area of $9 \mathrm{~mm}^{2}$ on the labial surface was exposed.

For the spectroscopy and erosion analysis, cylindrical enamel specimens $(n=12)$ with a 3 -mm diameter were obtained from the labial surface of the bovine crowns using a custom-made diamond-coated trephine mill. The specimens' heights were standardized to $2 \mathrm{~mm}$ by wearing down the dentin surface with watercooled SiC abrasive papers (\#1,200 grit, FEPA P, Struers).

For the erosion analysis, the cylindrical specimens were embedded in self-curing acrylic resin using a silicone mold $(6 \mathrm{~mm}$ in diameter and $3 \mathrm{~mm}$ in depth), leaving a $0.1-\mathrm{mm}$ enamel projection as previously described [Ávila et al., 2017]. The specimens were then ground flat and polished with water-cooled sequential $\mathrm{SiC}$ abrasive papers (\#1,200, \#2,400, and \#4,000 grit, FEPA P, Struers) coupled in a polishing machine at $300 \mathrm{rpm}$ for 30,60, and $120 \mathrm{~s}$, respectively. Specimens were sonicated in deionized water for 10 min after each paper grit change. The specimens presenting cracks and imperfections under the stereomicroscope examination $(\times 20$; Stemi 2000, Carl Zeiss, Oberkochen, Germany) were replaced. After preparation, the specimens were stored in relative humidity at $4{ }^{\circ} \mathrm{C}$ to avoid dehydration.

\section{Solution Preparation}

The following surfactant agents were tested: SLS (Synth, Diadema, Sao Paulo, Brazil), CAPB (Emfal, Belo Horizonte, Minas Gerais, Brazil), and P20 (Kotilen V1, Kolb, Moerdijk, the Netherlands). The concentrations tested were 1 and $1.5 \%$. The solutions were prepared by diluting the surfactants in water, under agitation, until achieving the concentration in volume for each group. Table 1 shows the chemical properties of all the surfactants.

For the groups containing fluoride, $275 \mathrm{ppm}$ of $\mathrm{NaF}$ was added to the solution in order to simulate a dentifrice with $1,100 \mathrm{ppm}$. This fluoride concentration was used to simulate the 1:3 dilution that occurs with the saliva during brushing [Duke and Forward, 1982].

\section{Surface Wettability - Contact Angle Characterization}

The polished crown specimens were divided into 7 groups $(n=$ 5 ) according to the surfactants (SLS, CPB, and P20) and the concentrations ( 1 and 1.5\%) used. For the contact angle analysis, the solutions were tested without fluoride. The control group was ultrapure water. The specimens were immersed in each group's respective solution for 2 min under agitation $(60 \mathrm{rpm}$ - Kline shaker, TS2000A, Biomixer), then placed on absorbent paper to dry before the measurements. This was performed due to the presence of wa- 
Table 1. Chemical properties of the surfactants

\begin{tabular}{llll}
\hline & $\begin{array}{l}\text { SLS } \\
\text { anionic }\end{array}$ & $\begin{array}{l}\text { CAPB } \\
\text { amphoteric }\end{array}$ & $\begin{array}{l}\text { P20 } \\
\text { nonionic }\end{array}$ \\
\hline Chemical formula & $\mathrm{C}_{12} \mathrm{H}_{25} \mathrm{SO}_{4} \mathrm{Na}$ & $\mathrm{C}_{19} \mathrm{H}_{38} \mathrm{~N}_{2} \mathrm{O}_{3}$ & $\mathrm{C}_{58} \mathrm{H}_{114} \mathrm{O}_{26}$ \\
Molar mass, g/mol & 288.4 & 342.5 & $1,227.5$ \\
Density, g/cm & 1.05 & 1.05 & 1.10 \\
Solution pH & 10.5 & 5.1 & 5.3 \\
$\mathrm{CMC}, \mathrm{mM}$ & 8.2 & 0.28 & 0.08 \\
CMC according to tested concentration, $\mathrm{mM}$ & $1 \%: 36.4$ & $1 \%: 30.6$ & $1 \%: 8.9$ \\
& $1.5 \%: 546$ & $1.5 \%: 45.9$ & $1.5 \%: 13.4$ \\
\hline
\end{tabular}

CMC, critical micellar concentration.

ter that might possibly increase the wettability of solid surfaces [Zhang et al., 2015].

The contact angle of the enamel surfaces was measured using the sessile drop analysis system (Theta Lite, Biolin Scientific, Stockholm, Sweden), with ultrapure water used as the probe's liquid. After dropping the water, a 20-s pause was given to let the drop rest. Pilot investigations showed that this time is required for achieving equilibrium between the water and the surface, with little change in the contact angle. After the rest period, a dedicated software (One Attension, Biolin Scientific, Stockholm, Sweden) was used to measure the right and left contact angles for $10 \mathrm{~s}$, and those measurements were then averaged.

\section{Spectroscopy Analysis - FTIR Assessment}

For the spectroscopy analysis, the polished enamel specimens $(n=12)$ were divided into the same 7 groups described for the contact angle analysis. The initial absorbance was obtained from all specimens using a FTIR spectrometer (Frontier; Perkin Elmer, MA, USA). The equipment was calibrated to 32 spectra per second with a resolution of $4 \mathrm{~cm}^{-1}$, and the spectra of the specimens were obtained from 600 to $4,000 \mathrm{~cm}^{-1}$.

After the initial measurements, the specimens were immersed in $2 \mathrm{~mL}$ of each group's respective solution for $2 \mathrm{~min}$ under agitation. Then, they were immersed in human saliva for $120 \mathrm{~min}$ for EAP formation. The saliva was previously collected from 20 donors (University Ethics Committee approval, protocol 367.946) under stimulation by chewing Parafilm M (Bemis Company Inc., Neenah, WI, USA), $2 \mathrm{~h}$ after breakfast and toothbrushing with a fluoride-free dentifrice. The donors were selected according to their salivary flow (stimulated flow higher than $0.8 \mathrm{~mL} / \mathrm{min}$ and unstimulated flow higher than $0.2 \mathrm{~mL} / \mathrm{min}$ ), had no health disease, and were not pregnant. Saliva was collected in cooled Falcon tubes, then mixed to form a pool, centrifuged $\left(10,000 \mathrm{rpm} / 4^{\circ} \mathrm{C}, 5 \mathrm{~min}\right)$ [Masson et al., 2013] and frozen at $-80^{\circ} \mathrm{C}$ until the moment of use [Cheaib and Lussi, 2011].

Immediately after EAP formation, the specimens were placed on absorbent paper to dry with the enamel facing up, and the final spectra were obtained with the same parameters described for the initial ones. The adsorbed proteins were quantified by the comparison of the amide I $\left(1,648 \mathrm{~cm}^{-1}\right)$ and amide II $\left(1,517 \mathrm{~cm}^{-1}\right)$ bands, which corresponds to the $\beta$-sheet and $\alpha$-helix structures, respectively, found in proteins such as $\alpha$-amylase, albumin, mucin, and proline-rich proteins [Caetano Junior et al., 2015]. The 980 $\mathrm{cm}^{-1}$ band corresponds to the phosphate found in hydroxyapatite and was used as the internal control. The spectra were submitted to baseline correction and normalized (between 0 and 1). After that, the absorbance increase was calculated using the following formula: $\% \mathrm{~A}=\left(\left[\mathrm{A}_{\mathrm{f}} / \mathrm{A}_{\mathrm{i}}\right]-1\right) \times 100$, in which \%A refers to the absorbance increase, $A_{f}$ refers to the final values, and $A_{i}$ to the initial values.

\section{Erosion Analysis - Initial Microhardness and Profilometry}

The cylindrical embedded enamel specimens were submitted to the initial microhardness $\left(\mathrm{SMH}_{\mathrm{i}}\right)$ measurements using a Knoop microhardness tester (FM-700, Future-Tech, Tokyo, Japan) adjusted to a $50-\mathrm{g}$ load for $10 \mathrm{~s}$. Three indentations were performed $100 \mu \mathrm{m}$ apart from each other and the values averaged. The mean microhardness value for all specimens was obtained $(326.8 \pm 34.7)$, and those presenting a value difference higher than $\pm 10 \%$ were replaced.

The baseline profiles of all specimens were obtained using a contact profilometer (MaxSurf XT 20, Mahr-Göttingen, Germany). Two parallel grooves were made at the resin, close to the specimen, in order to produce orientation guides during the profile readings. The profilometer diamond stylus moved from the first reference area in the acrylic resin to the second one ( $4.2 \mathrm{~mm}$ long) with a constant speed of $0.5 \mathrm{~mm} / \mathrm{s}$. Three profile measurements were performed for each specimen at intervals of $0.25 \mathrm{~mm}$.

After the initial microhardness and profile measurements, the specimens were divided into 14 groups $(n=12)$ according to the surfactant type (SLS, CAPB, P20), concentration (1 and 1.5\%), and the presence or not of NaF. The negative control group was ultrapure water, and the positive control was a NaF solution (275 ppm).

\section{Erosive Cycle}

The erosive cycle consisted of demineralization/remineralization events, with 4 immersions in $0.3 \%$ citric acid ( $\mathrm{pH} 2.6-5 \mathrm{~min}$ each), 4 immersions in human saliva (120 min each), and 2 immersions in the surfactant solutions ( $2 \mathrm{~min}$ each). Figure 1 shows a schematic drawing of the erosive cycle. The cycle was repeated for 5 consecutive days, always initiated by immersion in human saliva to form the acquired pellicle (red dotted line in Fig. 1). The specimens were kept under $100 \%$ relative humidity overnight. The immersions in the surfactant solutions were made after the first and 


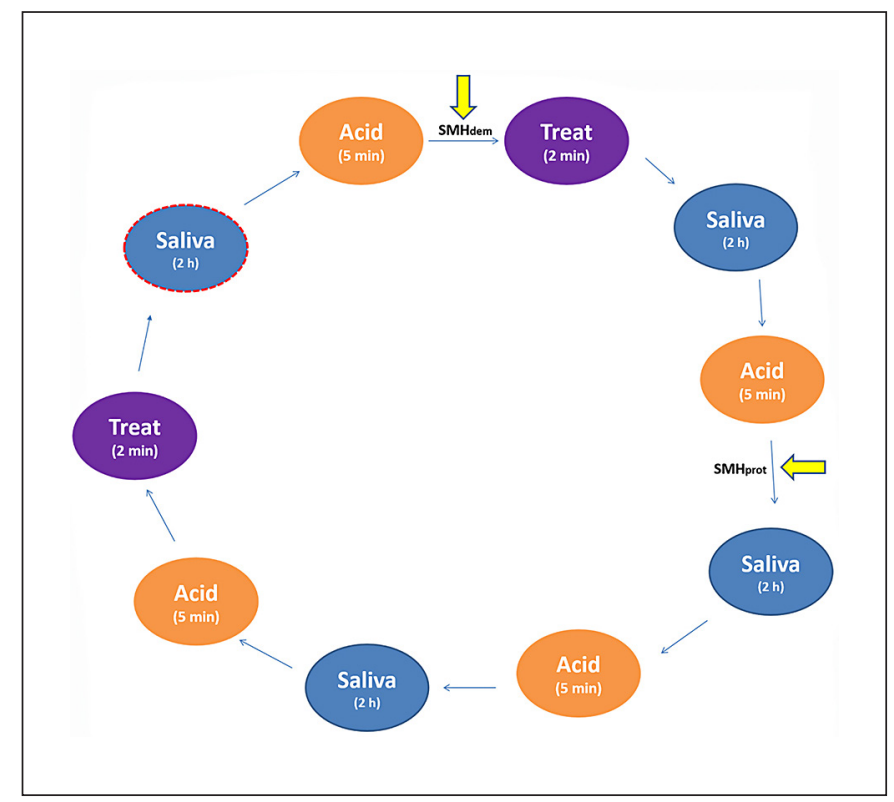

Fig. 1. Schematic chart of the erosive cycle. The red dashed line refers to the beginning of the erosive cycle each day. $\mathrm{SMH}_{\mathrm{dem}}$ refers to the microhardness after the first acid challenge. $\mathrm{SMH}_{\text {prot }}$ refers to the microhardness after the second acid challenge. $\mathrm{SMH}_{\mathrm{dem}}$ and $\mathrm{SMH}_{\text {prot }}$ were obtained only on the first day of the cycle.

the last acid challenge of the day, for $2 \mathrm{~min}$. The human saliva was used for EAP formation and remineralization, and was collected as previously described.

Final Microhardness and Profilometry

The initial erosion was evaluated by microhardness, which was assessed after immersing the specimens in the first acid challenge $\left(\mathrm{SMH}_{\mathrm{dem}}\right)$ to evaluate the demineralization potential of the citric acid. Then, microhardness was assessed again after the second acid immersion $\left(\mathrm{SMH}_{\text {prot }}\right)$ to evaluate the ability of the solutions to promote protection against a new erosive challenge (Fig. 1). All 3 microhardness data were obtained using the same parameter previously described. Microhardness data were presented in terms of relative percentage $\left(\% \mathrm{SMH}_{\mathrm{dem}}\right.$ and $\left.\% \mathrm{SMH}_{\text {prot }}\right)$ using the formulas: $\% \mathrm{SMH}_{\mathrm{dem}}=\left(\mathrm{SMH}_{\mathrm{dem}} / \mathrm{SMH}_{\mathrm{i}}\right) \times 100$ and $\% \mathrm{SMH}_{\text {prot }}=\mathrm{SMH}_{\text {prot }} /$ $\left.\mathrm{SMH}_{\mathrm{i}}\right) \times 100$.

The enamel loss was assessed by profilometry after the fifth day of the cycle. The specimens were positioned in a custom-made setting device in order to guarantee the exact replacement of the specimens after the experimental assessments. The final profiles were obtained with the same parameters previously described for the baseline ones. The surface loss $(\mu \mathrm{m})$ was calculated by the subtraction of the final profiles from the baseline profiles, with the previously described grooves as guides, using a dedicated software (MarSurf XCR 20 4.50-07 SP3, 2011).

\section{$\mathrm{KOH}$-Soluble Fluoride Determination}

The amount of $\mathrm{KOH}$-soluble fluoride was assessed after the profilometric analysis, using a previously described method
Table 2. Mean and standard deviation (in degrees) for the contact angle in all groups

\begin{tabular}{llcl}
\hline & $1 \%$ & $1.5 \%$ & $\begin{array}{l}p(t \text { test: } \\
\text { concentration })\end{array}$ \\
\hline SLS & $41.3 \pm 7.0$ & $30.7 \pm 9.2$ & 0.608 \\
CAPB & $20.0 \pm 10.6$ & $30.5 \pm 6.8$ & 0.405 \\
P20 & $50.0 \pm 6.4^{*}$ & $45.0 \pm 12.1^{*}$ & 0.244 \\
Water (control) & \multicolumn{3}{c}{$58.6 \pm 7.5^{*}$} \\
\hline
\end{tabular}

The asterisk shows values similar to that of the control group.

[Caslavska et al., 1975]. Therefore, the specimens were individually stored in plastic containers with $0.5 \mathrm{~mL}$ of $1 \mathrm{M} \mathrm{KOH}$ solution, under agitation and at room temperature for $24 \mathrm{~h}$. After this, 0.25 $\mathrm{mL}$ of the solution was transferred to another container with 0.25 $\mathrm{mL}$ of $1 \mathrm{M} \mathrm{HClO}_{4}$, and to this solution, $0.5 \mathrm{~mL}$ of TISAB II buffer was added.

The fluoride content was determined by an ion-selective electrode (Perfection, Mettler Toledo, Schwerzenbach, Switzerland), using a standard calibration curve prepared from solutions with a known concentration to define the fluoride concentration in the samples. The concentration of fluoride was expressed in $\mu \mathrm{g} / \mathrm{cm}^{2}$ ( $\mu \mathrm{g} \mathrm{F}^{-} / \mathrm{cm}^{2}$ enamel), and was measured using the formula $\mathrm{Cf}=$ $\mathrm{F}^{-} / \mathrm{A}$, in which $\mathrm{F}^{-}$refers to the fluoride content in $\mu \mathrm{g}$ and $\mathrm{A}$ refers to the specimen area $\left(A=\pi \times r^{2}\right.$, in which $\pi$ is equal to 3.14 and $r$ is the specimen radius defined in $0.15 \mathrm{~cm}$ ).

\section{Statistical Analysis}

Normality and homoscedasticity assumptions (Shapiro-Wilk and Levene tests) were checked for all data analysis. The contact angle data were submitted to 1 -way ANOVA $(p<0.05)$. Dunnett's test was performed to check the differences between the surfactant and the control group, and the Student $t$ test was applied to check for differences between the concentrations. The microhardness and profilometry data were submitted to 2 -way ANOVA $(p<$ 0.05 ), followed by the Dunnett test to compare the surfactant solutions with both control groups (water and $\mathrm{NaF}$ solution). The $\mathrm{Si}$ dak test was also applied to surface loss data. The comparison between the surfactant concentrations was made by the Student $t$ test. Fluoride data and absorbance values failed the normality test, and the Kruskal-Wallis test was applied $(p<0.05)$, followed by the Dunn test.

\section{Results}

The 1-way ANOVA performed for the contact angle characterization data showed significant differences among the groups tested $(p<0.0001)$. The Dunnett test revealed that SLS and CAPB in both concentrations decreased the contact angle between water and the enamel surface, while P20 presented values similar to the control (Table 2). Regarding the different concentrations, the 
Fig. 2. Box plot distribution of absorbance increase (\%) for all groups tested at amide I and amide II regions.
Fig. 3. a Water spectra showing peaks between 2,900 and 3,600 $\mathrm{cm}^{-1}$. b An example of initial (blue) and final (red) spectra from a specimen of the control group with the phosphate $\left(\mathrm{PO}_{4}^{3-}\right)$, carbonate $\left(\mathrm{CO}_{3}^{2-}\right)$, and organic compound peaks $\left(\mathrm{CH}_{2} / \mathrm{CH}_{3}\right)$. The star symbol indicates an absorbance increase both in the water peak (a) and in the enamel after pellicle formation (b - red line).
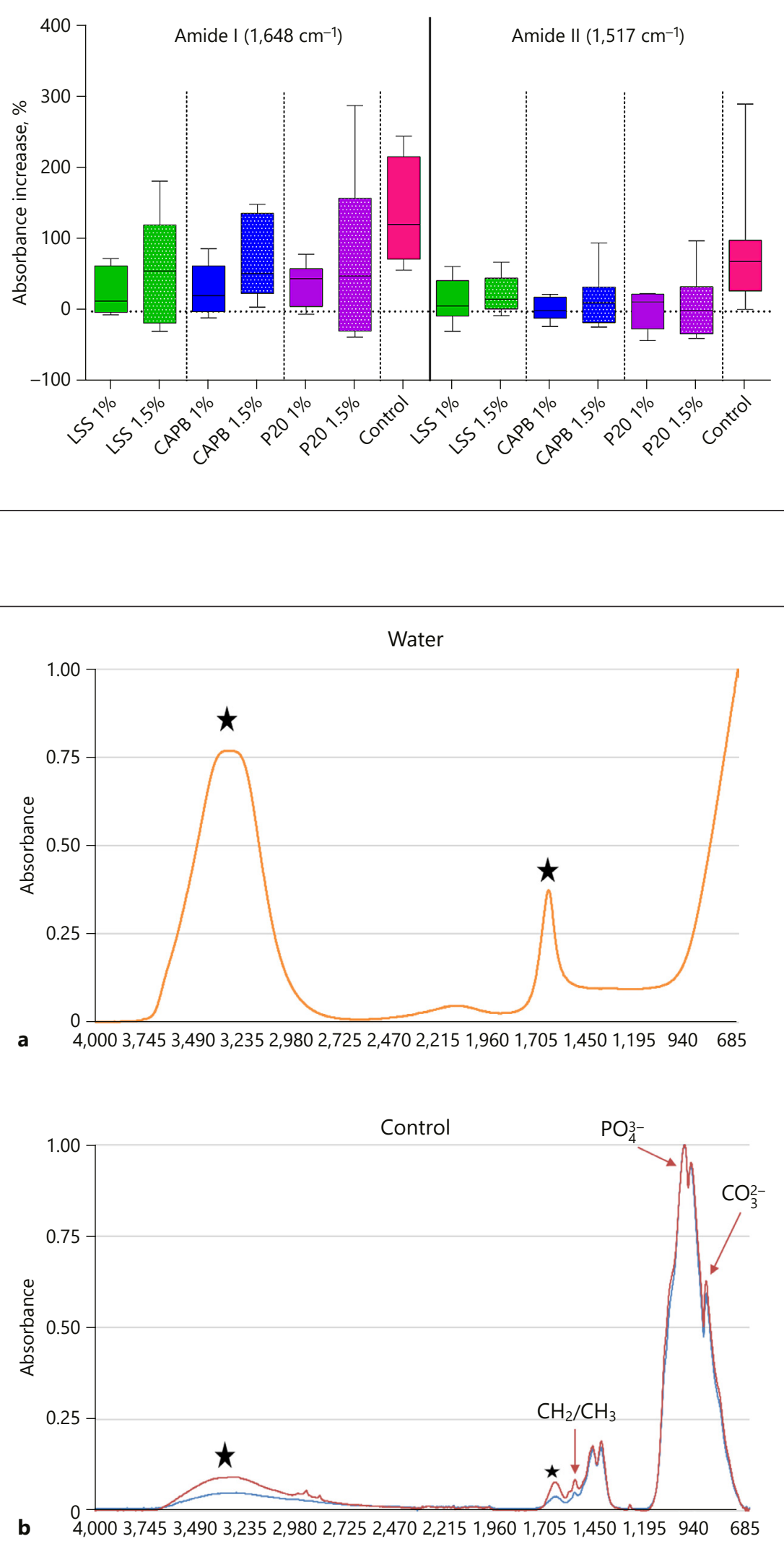
Table 3. Mean and standard deviation for $\mathrm{SMH}_{\mathrm{dem}}, \mathrm{SMH}_{\text {prot }}$ (relative percentage, measured after erosion), and surface loss ( $\left.\mu \mathrm{m}\right)$ for all groups tested

\begin{tabular}{|c|c|c|c|c|c|c|c|}
\hline & & \multicolumn{2}{|l|}{$\% \mathrm{SMH}_{\mathrm{dem}}$} & \multicolumn{2}{|l|}{$\% \mathrm{SMH}_{\text {prot }}$} & \multicolumn{2}{|l|}{ Surface loss } \\
\hline & & without $\mathrm{NaF}$ & with $\mathrm{NaF}$ & without $\mathrm{NaF}$ & with $\mathrm{NaF}$ & without $\mathrm{NaF}$ & with $\mathrm{NaF}$ \\
\hline CAPB & $\begin{array}{l}1.0 \% \\
1.5 \%\end{array}$ & $\begin{array}{l}81.8(7.7) \mathrm{Aa} \\
80.0(5.6) \mathrm{Aa}\end{array}$ & $\begin{array}{l}77.8(6.4) \mathrm{Aa} \\
81.6(3.9) \mathrm{Aa}\end{array}$ & $\begin{array}{l}55.8(4.8) \mathrm{Aa} \\
59.3(7.0) \mathrm{Ba}\end{array}$ & $\begin{array}{l}60.0(3.5) \mathrm{Aa} \\
63.2(5.3) \mathrm{Aa}\end{array}$ & $\begin{array}{l}2.91(0.82) \mathrm{Ba} \\
2.96(0.76) \mathrm{Ba}\end{array}$ & $\begin{array}{l}2.68(0.91) \mathrm{Aa} \\
2.37(0.62) \mathrm{Aa}\end{array}$ \\
\hline Control & - & $76.4(7.1) \mathrm{Aa}$ & $76.2(5.8) \mathrm{Aa}$ & $52.3(6.4) \mathrm{Aa}$ & $58.8(7.5) \mathrm{Aa}$ & $3.86(0.76) \mathrm{Aa}$ & $2.59(0.66) \mathrm{Ab}$ \\
\hline
\end{tabular}

Uppercase letters show differences within columns for all surfactants and the control group (Dunnett test). Lowercase letters show differences within lines (presence of NaF; Tukey test). The $¥$ symbol shows difference between the concentrations for each surfactant (Student $t$ test).

Student $t$ test showed no differences between 1 and 1.5\% for all surfactants tested (Table 2).

For the FTIR analysis, the Kruskal-Wallis test revealed no differences among the groups for both bands: amide I, $p=0.053$ and amide II, $p=0.059$. Figure 2 shows the box plot distribution for all groups. Despite the statistical results, a significant increase in the absorbance between 3,400 and $3,600 \mathrm{~cm}^{-1}$ (Fig. 2) was observed. This increase, associated with the increase at $1,648 \mathrm{~cm}^{-1}$, could indicate the presence of water in the specimen, which could have interfered with the final absorbance analysis (Fig. 3).

Regarding the erosion analysis, 2-way ANOVA showed no differences among the surfactants $(p=0.403)$ for microhardness values $\left(\mathrm{SMH}_{\mathrm{dem}}\right)$, regardless of the presence or not of NaF, as shown in Table 3 that presents the relative percentage of microhardness.

For the $\mathrm{SMH}_{\text {prot }}$ values, the Student $t$ test revealed that the concentration factor showed significant differences only for SLS without fluoride, with lower concentration presenting lower microhardness values. The 2-way ANOVA showed differences among the surfactants $(p<0.0001)$ and for the presence of $\mathrm{NaF}(p<0.0001)$. The comparison test adopted was Dunnett (all groups without $\mathrm{NaF}$ compared with the water control group, and all groups with $\mathrm{NaF}$ compared with the $\mathrm{NaF}$ solution group). It was observed that $1.5 \%$ CAPB presented higher microhardness values than the control group (Table 3). The SLS associated with $\mathrm{NaF}$, in both concentrations, presented lower values than the $\mathrm{NaF}$ solution group. Regarding the presence and absence of $\mathrm{NaF}$, the Tukey test revealed that there were no differences between presence and absence of fluoride for all tested groups (Table 3).
For the enamel loss profilometry analysis, 2-way ANOVA showed significant differences for the surfactant $(p=0.019)$ and for the presence of $\mathrm{NaF}(p<0.0001)$. The Dunnett test revealed that CAPB in both concentrations and $1 \%$ P20 presented a lower surface loss than the control group. For the groups associated with fluoride, the Dunnett test showed no differences with the NaF solution. Regarding the protective effect promoted by the fluoride, the Sidak test showed that only the NaF solution presented a lower surface loss than the control group. All surfactants associated with fluoride presented similar values with the $\mathrm{NaF}$ solution group. Table 3 shows the mean and standard deviation for surface loss after 5 days.

Finally, the $\mathrm{KOH}$-soluble fluoride content was assessed in the solutions containing NaF. The Kruskal-Wallis test revealed significant differences among the groups $(p<0.001)$. The Dunn test showed that all surfactant solutions presented a lower fluoride concentration than the $\mathrm{NaF}$ solution group, except for $1.5 \% \mathrm{P} 20$, which presented similar values (Table 4). The statistical analysis was performed only in the groups containing fluoride, as the values obtained from the groups without fluoride were frequently below the detection level of the electrode used and therefore would lead to false results.

\section{Discussion}

The contact angle analysis allowed the rejection of the first null hypothesis, since the enamel surface energy changed after the treatment with surfactants, with SLS and CAPB in both concentrations increasing the enamel 
Table 4. Mean and standard deviation for $\mathrm{KOH}$-soluble fluoride $\left(\mu \mathrm{g} / \mathrm{cm}^{2}\right)$ on enamel surface

$\mathrm{KOH}$-soluble fluoride

\begin{tabular}{lll}
\hline $\mathrm{SLS}+\mathrm{NaF}$ & $1.0 \%$ & $0.247 \pm 0.354 \mathrm{~A}$ \\
$\mathrm{CAPB}+\mathrm{NaF}$ & $1.5 \%$ & $0.858 \pm 0.104 \mathrm{~A}$ \\
& $1.0 \%$ & $0.647 \pm 0.448 \mathrm{~A}$ \\
$\mathrm{P} 20+\mathrm{NaF}$ & $1.5 \%$ & $0.926 \pm 0.179 \mathrm{~A}$ \\
& $1.0 \%$ & $0.705 \pm 0.431 \mathrm{~A}$ \\
$\mathrm{NaF}$ (positive control) & $1.5 \%$ & $0.941 \pm 0.126 \mathrm{~B}$ \\
& - & $1.597 \pm 0.253 \mathrm{~B}$ \\
\hline
\end{tabular}

Uppercase letters indicate significant differences among the groups $(\mathrm{p}<0.05)$.

surface wettability. The concentrations used in this study were chosen based on previous studies [Fisher et al., 2002; Strand, 2011; Masters et al., 2012] and were higher than the critical micellar concentration of the surfactants (Table 1). The critical micellar concentration is defined as the maximum concentration in which the surfactants can be used without forming micelles [Bergstrom, 2015]. When surfactants are used in concentrations higher than their critical micellar concentration, the molecules do not find free surfaces on which to bind, thus they start aggregating between each other forming spherical or cylindrical structures, called micelles. In aqueous systems, the conformation of these micelles tends to present a core composed of the hydrophobic hydrocarbon chains (such chains turn to the center, repelled by water), with the exterior formed by the polar head of the molecule [Bruce et al., 2002]. The head is composed of sulfate ions in SLS, quaternary nitrogen ions in $\mathrm{CAPB}$, and ethylene oxide ions in P20.

The increase in surface wettability promoted by SLS might be explained by the interactions of sulfate and sodium ions with the calcium from hydroxyapatite, as shown in other studies [Barkvoll et al., 1988a, b; Jones et al., 2014]. Even though the micelles from SLS tend to expose the hydrocarbon chains (hydrophobic) on its external surface, due to the lower amount of the sulfate radical, it has been shown that they allow the entrance of water into its interior [Chun et al., 2015].

Although no studies were found showing that the CAPB binds to hydroxyapatite, it might be speculated that the quaternary nitrogen ions from CAPB micelles bind to phosphate sites and also interact with water, increasing enamel wettability. Regarding P20, the results show no change on the enamel surface, indicating that

Influence of Surfactants on Dental Erosion strong chemical interactions between this agent and hydroxyapatite are unlikely to happen.

Although previous studies have reported an influence of SLS on the enamel pellicle, causing a delay in its formation and also leading to a thinner film [Rykke et al., 1990; Veeregowda et al., 2011], the analysis of adsorbed proteins on enamel in this study did not reveal an influence of SLS, or the other surfactants tested, over EAP formation. However, this result must be carefully analyzed, since the presence of water inside the enamel prisms (and in the pellicle) might have influenced the absorbance patterns, leading to false-positive results (star symbol in Fig. 3). Additional analysis should be conducted to better assess the effect of surfactants over the pellicle.

The initial erosion analysis showed that, after the second erosive challenge ( $\left.\mathrm{SMH}_{\text {prot }}\right)$, the SLS in both concentrations presented similar values to the negative control group, indicating that it does not affect the pellicle formation. Thus, the second null hypothesis was denied. Although previous studies have shown that SLS causes a delay in the pellicle formation [Rykke et al., 1990] and also produces a thinner film, which is less able to protect enamel from acids [Veeregowda et al., 2011], this was not observed for the short-duration erosive situation.

However, the association of SLS with $\mathrm{NaF}$ led to a reduction in the enamel microhardness when compared to the NaF solution group. This indicates that the SLS competes with the fluoride for the calcium binding sites, avoiding or decreasing the amount of $\mathrm{NaF}$ that can interact with hydroxyapatite, thus reducing its protective effect. It has been previously shown that SLS decreases the sodium fluoride deposition on enamel and increases the solubility of the calcium fluoride $\left(\mathrm{CaF}_{2}\right)$ precipitates formed [Barkvoll et al., 1988b]. The formation of $\mathrm{CaF}_{2}$ precipitates on the enamel surface is the main component responsible for the $\mathrm{NaF}$ protection in erosive situations [Magalhaes et al., 2009, 2011]. It is believed that these precipitates work as a mineral barrier to be dissolved during acid challenges [Ganss et al., 2001], therefore, the understanding of the interaction between surfactants and $\mathrm{NaF}$ is important for erosion control treatments. However, it must be highlighted that the $\mathrm{CaF}_{2}$ formed depends on the fluoride concentration, $\mathrm{pH}$, and application time [Petzold, 2001; Scaramucci et al., 2013]. In the tested concentration $(275 \mathrm{ppm})$ and short application time (2 $\mathrm{min})$, it is unlikely that $\mathrm{CaF}_{2}$ precipitates are formed; instead, it can be speculated that a nonspecific fluoride phase adsorbed onto the enamel surface. This is believed to make the fluoride ion available to reduce the hydroxyapatite demineralization rate during erosive situations [Scara- 
mucci et al., 2013]. Nevertheless, even with the fluoride protection decrease associated with SLS, and the lower $\mathrm{KOH}$-soluble fluoride values found in both concentrations on the enamel surface, the profilometry results showed that this potential deleterious effect was not maintained with successive erosive situations. The enamel surface loss after a 5-day cycle was similar to the control group in both concentrations tested and associated or not with fluoride. Thus, the presence of SLS does not seem to jeopardize the protection provided by the pellicle and the fluoride in long-lasting erosive situations.

Regarding the effects of CAPB on initial erosion, it was observed that it was able to protect enamel when used at $1.5 \%$, enhancing the possibility of chemical interactions between this agent and hydroxyapatite. When associated with $\mathrm{NaF}$, this surfactant was also able to protect enamel in both concentrations tested, as it did not differ from the $\mathrm{NaF}$ group (positive control). As CAPB presents a positive radical (sodium ions), it does not compete with fluoride for calcium sites and, therefore, does not influence the fluoride protective effect. With the persistency of the erosive condition, CAPB was the only surfactant able to protect the enamel per se, promoting lower structural wear than the negative control group (water), and with similar results to the positive control group (NaF solution). The decrease in $\mathrm{KOH}$-soluble fluoride on the enamel surface found for CAPB (Table 4) supports the hypothesis that it alone exerts a protective effect. The results from CAPB indicate the possible deposition of this agent on the enamel, preventing direct contact of the acid with the surface, thus promoting the enamel's protection.

Regarding P20, a significant protective effect was not observed in both concentrations tested for the initial erosion; however, differently from SLS and CAPB, this agent showed no evidence of chemical interaction with hydroxyapatite (contact angle analysis). Also, the association of $\mathrm{P} 20$ with $\mathrm{NaF}$ did not show protective ability for initial erosion. The persistence of the erosive situations showed that the protection of P20 only happened when used in the lower concentration (1\%). No studies were found evaluating the relation of this surfactant with enamel; thus, the protective effect can only be speculated and might have happened due to its high molecular weight (Table 1). This may have promoted its deposition over the enamel surface, without chemical interactions, functioning as a temporary protective layer against acids.

Since the erosive process occurs in two distinct phases, enamel surface softening followed by structure loss with erosive situation persistence [Ganss et al., 2014], an in vitro study model that mimicked everyday situations was sought [West et al., 2011]. The adopted model consisted of 2 daily applications of the surfactant solutions (totaling $4 \mathrm{~min}$ ), 6 daily erosive challenges (totaling $30 \mathrm{~min}$ ), and 4 daily applications of human saliva (totaling $8 \mathrm{~h}$ per day) for enamel remineralization and pellicle formation. Citric acid is commonly used to simulate extrinsic erosion [Wiegand et al., 2008; Aykut-Yetkiner et al., 2014] and was used in this model. The model was repeated for 5 days to promote a measurable deleterious effect on the enamel surface [Barbour et al., 2011]. Considering that the intraoral $\mathrm{pH}$ after an acidic attack is reduced for up to several minutes, and the total erosion time in the present study lasted for only $2.5 \mathrm{~h}$, the erosive cycling in this study can be classified as relatively mild [Zanatta et al., 2017]. Future studies should aim to investigate the chemical interactions between CAPB and P20 to hydroxyapatite, and also the interaction of the surfactants with other fluoride compounds, such as stannous fluoride. In addition, as surfactants are commonly found in dentifrices, future studies should include abrasion cycles.

Therefore, it must be concluded that SLS and CAPB in both concentrations tested ( 1 and 1.5\%) increased enamel wettability, while $\mathrm{P} 20$ promoted no alteration on the enamel surface contact angle. SLS decreased the fluoride protection in the initial erosion, but this deleterious effect did not persist with the maintenance of the erosive cycle. CAPB in both concentrations and $1.0 \% \mathrm{P} 20$ protected the enamel against erosive structure loss, but this effect was not maintained when these surfactants were associated with fluoride.

\section{Acknowledgments}

The authors do not have any financial interests in the companies whose materials are included in this article. The work was supported by grants \#2013/12069-5, \#2013/16944-8, \#2014/064428, \#2017/13799-8, and \#2018/07003-9 São Paulo Research Foundation (FAPESP). The funders had no role in study design, data collection and analysis, decision to publish, or preparation of the manuscript.

\section{Disclosure Statement}

The authors declare no conflict of interests.

\section{Author Contributions}

Conception and design of the experiments were done by R.F.Z. and A.B.B. Performing the experiments were R.F.Z., D.M.S.A., and K.M.M. Analyzing the data was done by R.F.Z., C.R.G.T., and A.B.B. Writing the manuscript was done by R.F.Z., C.R.G.T., and A.B.B. 


\section{References}

Ávila DMS, Zanatta RF, Scaramucci T, Aoki IV, Ganss C, Klimek J, Schaffer U, Spall T: EffectiveTorres CR, Borges AB: Influence of bioadhesive polymers on the protective effect of fluoride against erosion. J Dent 2017;56:45-52.

Aykut-Yetkiner A, Wiegand A, Attin T: The effect of saliva substitutes on enamel erosion in vitro. J Dent 2014;42:720-725.

Barbour ME, Lussi A, Shellis RP: Screening and prediction of erosive potential. Caries Res 2011;45(suppl 1):24-32.

Barkvoll P, Embery G, Rolla G: Studies on the interaction between sodium lauryl sulfate and hydroxyapatite using Fourier transformed infrared spectroscopy. J Biol Buccale 1988a;16 75-79.

Barkvoll P, Rolla G, Lagerlof F: Effect of sodium lauryl sulfate on the deposition of alkali-soluble fluoride on enamel in vitro. Caries Res 1988b;22:139-144.

Bergstrom LM: Explaining the growth behavior of surfactant micelles. J Colloid Interface Sci 2015;440:109-118.

Bruce CD, Berkowitz ML, Perera L, Forbes MDE: Molecular dynamics simulation of sodium dodecyl sulfate micelle in water: micellas structural characteristics and counterion distribution. J Phys Chem 2002;106:3788-3793.

Buzalaf MA, Hannas AR, Kato MT: Saliva and dental erosion. J Appl Oral Sci 2012;20:493502.

Caetano PC Jr, Strixino JF, Raniero L: Analysis of saliva by Fourier transform infrared spectroscopy for diagnosis of physiological stress in athletes. Res Biomed Eng 2015;31:116-124.

-Caslavska V, Moreno EC, Brudevold F: Determination of the calcium fluoride formed from in vitro exposure of human enamel to fluoride solutions. Arch Oral Biol 1975;20:333-339.

Cheaib Z, Lussi A: Impact of acquired enamel pellicle modification on initial dental erosion. Caries Res 2011;45:107-112.

-Chun BJ, Choi JI, Jang SS: Molecular dynamics simulation study of sodium dodecyl sulfate micelle: water penetration and sodium dodecyl sulfate dissociation. Colloids Surf A Physicochem Eng Asp 2015;474:36-43.

Duke SA, Forward GC: The conditions occurring in vivo when brushing with toothpastes. $\mathrm{Br}$ Dent J 1982;152:52-54.

Featherstone JD, Lussi A: Understanding the chemistry of dental erosion. Monogr Oral Sci 2006;20:66-76.

Fisher WS, Gambogi JR, Joziak TM, Tavss AE: Dual component dentifrice composition for fluoridating teeth. USA Patent No EP 1076 550 B1. 2002. ness of two fluoridation measures on erosion progression in human enamel and dentine in vitro. Caries Res 2001;35:325-330.

Ganss C, Lussi A, Schlueter N: The histological features and physical properties of eroded dental hard tissues. Monogr Oral Sci 2014;25: 99-107.

Ganss C, Schlueter N, Hardt M, Schattenberg P, Klimek J: Effect of fluoride compounds on enamel erosion in vitro: a comparison of amine, sodium and stannous fluoride. Caries Res 2008;42:2-7.

Hannig C, Hannig M, Attin T: Enzymes in the acquired enamel pellicle. Eur J Oral Sci 2005; 113:2-13.

Jager DH, Vissink A, Timmer CJ, Bronkhorst E, Vieira AM, Huysmans MC: Reduction of erosion by protein-containing toothpastes. Caries Res 2013;47:135-140.

Jones SB, Barbour ME, Shellis RP, Rees GD: Interactions between dodecyl phosphates and hydroxyapatite or tooth enamel: relevance to inhibition of dental erosion. Colloids Surf B Biointerfaces 2014;117:193-198.

Lussi A, Carvalho TS: Erosive tooth wear: a multifactorial condition of growing concern and increasing knowledge. Monogr Oral Sci 2014; 25:1-15.

Lussi A, Schlueter N, Rakhmatullina E, Ganss C: Dental erosion - an overview with emphasis on chemical and histopathological aspects. Caries Res 2011;45(suppl 1):2-12.

-Magalhaes AC, Rios D, Honorio HM, Delbem AC, Buzalaf MA: Effect of 4\% titanium tetrafluoride solution on the erosion of permanent and deciduous human enamel: an in situ/ex vivo study. J Appl Oral Sci 2009;17:56-60.

Magalhaes AC, Wiegand A, Rios D, Buzalaf MA, Lussi A: Fluoride in dental erosion. Monogr Oral Sci 2011;22:158-170.

Masson N, Domingues RR, Cury JA, Paes Leme AF: Acidulated phosphate fluoride application changes the protein composition of human acquired enamel pellicle. Caries Res 2013;47:251-258.

Masters J, Pilch S, Sullivan R: Anti-erosion toothpaste composition. US Patent No US 2012051 466 A1. 2012.

Moore C, Addy M: Wear of dentine in vitro by toothpaste abrasives and detergents alone and combined. J Clin Periodontol 2005;32:12421246.

Neppelberg E, Costea DE, Vintermyr OK, Johannessen AC: Dual effects of sodium lauryl sulphate on human oral epithelial structure. Exp Dermatol 2007;16:574-579.

Petzold M: The influence of different fluoride compounds and treatment conditions on dental enamel: a descriptive in vitro study of the $\mathrm{CaF}_{2}$ precipitation and microstructure. Caries Res 2001;35(suppl 1):45-51.
Rantanen I, Nicander I, Jutila K, Ollmar S, Tenovuo J, Soderling E: Betaine reduces the irritant effect of sodium lauryl sulfate on human oral mucosa in vivo. Acta Odontol Scand 2002;60:306-310.

Rykke M, Rolla G, Sonju T: Effect of sodium lauryl sulfate on protein adsorption to hydroxyapatite in vitro and on pellicle formation in vivo. Scand J Dent Res 1990;98:135-143.

Scaramucci T, Borges AB, Lippert F, Frank NE, Hara AT: Sodium fluoride effect on erosionabrasion under hyposalivatory simulating conditions. Arch Oral Biol 2013;58:14571463.

Strand R: Oral care compositions which comprises stannous and potassium salts. US Patent No EP 2338464 A2. 2011.

Van der Mei HC, White DJ, Kamminga-Rasker HJ, Knight J, Baig AA, Smit J, Busscher HJ: Influence of dentifrices and dietary components in saliva on wettability of pellicle-coated enamel in vitro and in vivo. Eur J Oral Sci 2002;110:434-438.

Veeregowda DH, van der Mei HC, Busscher HJ, Sharma PK: Influence of fluoride-detergent combinations on the visco-elasticity of adsorbed salivary protein films. Eur J Oral Sci 2011;119:21-26.

Vukosavljevic D, Custodio W, Buzalaf MA, Hara AT, Siqueira WL: Acquired pellicle as a modulator for dental erosion. Arch Oral Biol 2014; 59:631-638.

West NX, Davies M, Amaechi BT: In vitro and in situ erosion models for evaluating tooth substance loss. Caries Res 2011;45(suppl 1):4352.

Wiegand A, Bliggenstorfer S, Magalhaes AC, Sener B, Attin T: Impact of the in situ formed salivary pellicle on enamel and dentine erosion induced by different acids. Acta Odontol Scand 2008;66:225-230.

Zanatta RF, Lungova M, Borges AB, Torres C, Sydow HG, Wiegand A: Microleakage and shear bond strength of composite restorations under cycling conditions. Oper Dent 2017; 42:E71-E80.

Zero DT: Dentifrices, mouthwashes, and remineralization/caries arrestment strategies. BMC Oral Health 2006; 16:S9.

Zhang YF, Zheng J, Zheng L, Zhou ZR: Effect of adsorption time on the adhesion strength between salivary pellicle and human tooth enamel. J Mech Behav Biomed Mater 2015;42: 257-266.
Influence of Surfactants on Dental Erosion 